\title{
Review of Remediation Technologies for Cadmium in soil
}

\author{
Xin Tang ${ }^{1, a, *}$, Yuqin $\mathrm{Ni}^{2, b, *}$ \\ ${ }^{1}$ Yangzhou University, Yangzhou, Jiangsu 225000, China \\ ${ }^{2}$ East China of University of Science and Technology, Shanghai 200000, China
}

\begin{abstract}
Heavy metal pollution in soil has seriously affected the living environment of human beings. Among all heavy metal pollution, cadmium $(\mathrm{Cd})$ is one of the most difficult to migrate pollutants in soil. In China, more than 11 provinces and 25 regions are rich in cadmium in the soil. At present, many researchers are looking for a proper $\mathrm{Cd}$ pollution remediation method. Through literature review and comparative analysis, this study summarized the main repair methods, including physical repair (digging and filling, electro kinetic remediation, frozen soil remediation technology, stabilization technology), chemical curing technology (chemical healing technology, chemical extraction), bioremediation technology (Phytoremediation technology, microbial remediation technology, animal repair technology), and joint repair (Chelating agent phytoremediation, microbial remediation). Finally, we explored the principles of these methods and compared their advantages and disadvantages. It was found that the application and selection of different treatment technologies depended on $\mathrm{Cd}$ rich soil area, Cd pollutant content, treatment time and other factors. In the future, the remediation of soil cadmium pollution should be scientifically selected according to the local actual situation and pay attention to the joint application of various methods.
\end{abstract}

\section{Introduction}

Cadmium is one of the five most toxic chemical elements (mercury, lead, cadmium, arsenic, and chromium). As cadmium is highly resistant to corrosion, damages to the soil caused by cadmium pollution is basically irreversible. Therefore, contaminated environment is difficult to recover from cadmium pollution. Cadmium toxicity and treatment are currently key research areas in soil environmental research $[1,2]$. Recently, a national report showed that the total excess rate of heavy metals in cultivated soil in China is $19.4 \%$, of which the excess rate of cadmium is $7.0 \%$, ranking first in Chinese soil pollutants [3]. Meanwhile, related research investigations have also confirmed that cadmium pollution is widespread in rice and other agricultural products, especially in the acid red soil regions of the south China [4-6] In this way, cadmium in the environment enters and influences the human body mainly through the soil-crop-food chain [7].

Nowadays, the research about cadmium absorption has already developed for many years. In this study, we made a comparison of different technologies for cadmium absorption in soil.

\section{Sources of Soil Cadmium Pollution and Current Situation}

\subsection{Formatting the title, authors and affiliations}

There are two main sources of cadmium in soil, which are material of nature and human activities. A natural metallic element, cadmium $(\mathrm{Cd})$ is generally present in shallow layers of the earth's crust. In general, the average value of cadmium in soil is $0.35 \mathrm{mg} / \mathrm{kg}$ around the world [8]. However, Cd is present at elevated levels in soils. Due to the irregular management of industrial and agricultural waste water and waste material, large amount of solid $\mathrm{Cd}$ or cadmium ion enter the soil. As for human related reasons that account for soil cadmium pollution, there are, in general, four types of human activities that all have significantly negative impact on the environment: 1) Atmosphere deposition; 2) Sewage irrigation; 3) Use of cadmium fertilizer; 4) Industrial waste stacking

\subsubsection{Cadmium in atmosphere deposition}

The industrial waste gas contains an amount of cadmium, especially factories producing pigments, dyes, voltage stabilizers and electroplating [9]. These kinds of industrials need $\mathrm{Cd}$ for relative products such as fragrances and batteries. In the process of production, waste gas containing $\mathrm{Cd}$ will be emitted to the air and

\footnotetext{
a Xin Tang: 181802117@yzu.edu.cn;

bYuqin Ni: 19003838@mail.ecust.edu.cn
} 
diffused with the wind and dust around the factories. In that case, the concentration of $\mathrm{Cd}$ in the atmosphere around the industrial area will increase. High concentrations of $\mathrm{Cd}$ can enter the soil through rainfall or sedimentation. Finally, Cd will accumulate in the soil, causing cadmium pollution [10].

\subsubsection{Sewage irrigation}

The industrial wastewater released by factories that produce plastic, dyes and paints contains a variety of heavy metals, including a large amount of $\mathrm{Cd}$. If the wastewater is not treated strictly up to standard or just discharged into rivers and lakes, the soil near water systems will be polluted by $\mathrm{Cd}$.

Accordingly, $\mathrm{Cd}$ in the water will enter the soil when sewage containing $\mathrm{Cd}$ is used to irrigate. Thus, the $\mathrm{Cd}$ pollution is more likely to take place in sewage irrigated farm around industrial, mining and suburban areas. According to statistics, industries discharge about 30 to 40 billion tons of untreated sewage every year [11]. The use of these industrial sewage for irrigation has caused serious heavy metal pollution.

\subsubsection{Use of cadmium fertilizer}

Fertilizer can increase the yield during the agriculture activities and many people increase the use of fertilizers in pursuit of high yields of crops. In that case, frequent use of cadmium fertilizer will certainly lead to $\mathrm{Cd}$ pollution. According to study findings and statistical analysis in Western countries, phosphate fertilizers contain more cadmium than nitrogen and potassium fertilizers [12]. It is also found that the average amount of cadmium in phosphate fertilizer can reach about 7.0 $\mathrm{mg} / \mathrm{kg}$, which can lead to $6.6 \times 104 \mathrm{~kg}$ of cadmium in soil [12]. That being so, long-term use of phosphate fertilizers can be one of influence factors of pollution.

\subsubsection{Industrial waste stacking}

In heavy metal tailings, smelting waste residues and slag piles, considerable amounts of acid wastewater will be produced. During mining, various heavy metal ions will dissolve in acid wastewater produced. Due to that, cadmium will enter the soil along the acid water. So industrial waste is also an essential reason for $\mathrm{Cd}$ pollution.

\subsection{Current status of soil cadmium pollution}

In China, more than 11 provinces and 25 districts have cadmium enrichment in soil [13]. Agricultural soil contaminated by a variety of heavy metals accounts for about $16.7 \%$ of the crop planting area, and more than $40 \%$ of the soil is contaminated by Cd [14]. In San Francisco, USA, studies showed that among soil samples from 91 vegetable gardens, the most $(>75 \%)$ gardens had heavy metal content exceeding the California human health screening level, and $\mathrm{Cd}$ was the highest, reaching $84 \%$ [15]. According to these data, it is inferred that Cd pollution in soil is a major problem in China and around the world. So many researchers are finding various methods and technologies to solve this global issue.

\section{Repair methods}

\subsection{Physical repair methods}

\subsubsection{Digging and filling}

Excavation and filling mainly include borrowing soil, filling soil and farming. Borrowing soil refers to covering the contaminated soil layer with clean soil obtained from other places, and then isolating $\mathrm{Cd}$ pollution through a low permeability clay layer. Borrowed soil and soil substitutes are suitable for remediation of heavily polluted soil [16].

Generally, the advantage of excavation and filling measures is that $\mathrm{Cd}$ pollution can be completely removed quickly and effectively. On the other hand, they require a lot of engineering work and investment, including destroying the soil structure, transferring the risk of soil pollution, and causing the decline of soil fertility. Therefore, excavation and filling are mainly suitable for repairing small and heavily polluted fields, however, not suitable for large-scale sites where the soil is slightly to moderately polluted, as shown in Table 1 .

\subsubsection{Electro-kinetic remediation}

Electro-kinetic remediation is a physical technique used to separate metals from contaminated soil [17]. This remediation method was originally used to extract metals and organic chemicals from contaminated soil and groundwater. When a low voltage of direct current (the cross-sectional area is in the order of $\mathrm{mA} / \mathrm{cm} 2$ ) or the potential gradient of a low electric field (in the order of $\mathrm{V} / \mathrm{cm}$ in the distance between the electrodes) is applied, the metals in the soil will migrate through the electricity [18]. The percolation and electrophoresis migrate to the electrode chamber, through electroplating, adsorption to the electrode, precipitation or co-precipitation occurs on the electrode, and finally the $\mathrm{Cd}$ accumulated on the electrode is removed by pumping water near the electrode or complexing with ion exchange resin.

The advantages of electric repair are that 1) it does not disturb the soil layer; 2) it is easy to operate; and 3) it has high repair efficiency. On the other hand, this technology changes the physical and chemical properties of the soil, has low selectivity to different pollutants, and has a high ecological risk in terms of soil acidification. Moreover, electric repair is time-consuming and expensive [19].

\subsubsection{Frozen soil technology}

Frozen soil remediation technology is to arrange pipelines at equal distances underground for known pollution sources, and then pass harmless freezing solvents to freeze the moisture in the soil, thus forming 
an underground frozen soil barrier, which can prevent soil or groundwater Pollutants diffuse [20]. But the polluted soil cannot be purified, thus there still exists problems of large engineering volume and high input cost.

\subsubsection{Stabilization}

According to the Environmental Protection Agency(EPA)'s definition [21], stabilization technology refers to encapsulating pollutants in an inert substrate, or adding low-permeability materials outside the pollutants to limit the migration of pollutants by reducing the leaching area exposed by the pollutants. Commonly used $\mathrm{S} / \mathrm{S}$ cementitious materials can be divided into the following 4 categories [22]: 1) Inorganic binding substances, such as cement, lime and other substances; 2) Organic binders, such as asphalt and other thermoplastic materials; 3) Thermal hardening organic polymer substances, such as urea, phenolic plastics and epoxides and other organic substances; and 4) Glassy substances.

Due to technical and cost reasons, inorganic materials such as cement and lime are the most widely used, accounting for $94 \%$ of the number of projects, organic binders account for $3 \%$ of the number of projects, and both inorganic and organic binders are used in projects. Three percent of the number of projects [23].

\subsubsection{Cement curing}

Cement-based binders are commonly used materials in $\mathrm{S} / \mathrm{S}$ technology. In the past 50 years, the technology of cement immobilization treatment of heavy metals has been widely used. Cement is an inorganic cementing material. After hydration reaction [24], a hard cement solidification body could be formed. The mechanism of cement solidification is taken place mostly in the water of the cement. In the process of chemical conversion, heavy metals can react with cement through various methods such as adsorption, chemical absorption, sedimentation, ion exchange, passivation, and finally stay in the hydrated silicic acid formed by cement hydration in the form of hydroxides or complexes. As for the salt colloid surface, the addition of cement also provides an alkaline environment for heavy metals, which inhibits the penetration of heavy metals [25-27].

Nevertheless, cement curing has some disadvantages. For example, most sulfates have a significant corrosive effect on the hardened paste of Portland cement. This is largely due to the fact that various sulfates such as sodium sulfate and potassium sulfate can interact with Portland cement. The calcium hydroxide contained in the slurry reacts to form calcium sulfate, or further reacts with calcium aluminate hydrate to form vanadinite, which greatly increases the solid phase volume and causes swelling. In addition, Portland cement has poor acid resistance. Acid rain is more serious in many areas of China, and the lack of acid resistance of cement makes the heavy metals solidified by cement re-dissolve in an acid environment.

\subsubsection{Lime/volcanic ash solidification}

According to the pozzolanic reaction, in the presence of water, fine pozzolanic powder can react with alkali metal and alkaline earth metal hydroxides at room temperature. Lime/Pozzolanic solidification technology refers to the incineration of lime and garbage Fly ash, cement kiln dust, and melting furnace slag, and other substances with Pozoro reaction, are used as a hazardous waste $\mathrm{S} / \mathrm{S}$ method to solidify the substrate.

In general, the effect of lime on soil heavy metals is to increase soil $\mathrm{pH}$, and $\mathrm{Ca} 2+$ has an antagonistic effect on $\mathrm{Cd} 2+$, so lime is considered to be an effective measure to inhibit cadmium pollution and promote the absorption of cadmium by plants on acid soils in $\mathrm{Cd}$ pollution[28]. Generally, applying $750 \mathrm{~kg} \cdot \mathrm{hm}-2$ lime to the soil can reduce the effective content of heavy metal $\mathrm{Cd}$ in the soil by about $15 \%$, which has a certain effect on reducing the absorption of $\mathrm{Cd}$ by crops.

\subsubsection{Plastic material containment curing}

The plastic material containment method belongs to the organic $\mathrm{S} / \mathrm{S}$ processing technology. From the performance of the material, the technology can be divided into thermoset plastic containment and thermoplastic material containment.

Thermosetting plastic refers to a material that changes from a liquid to a solid and hardens when heated, and will not re-liquefy or soften even if heated again in the future. It is actually a cross-chain polymerization process from small molecules to large molecules. Currently, the most commonly used materials include urea-formaldehyde resin, polyester, polybutadiene, phenolic resin, epoxy resin. Adopt unsaturated polyester resin, epoxy resin, phenolic resin cementing material, catalyst as auxiliary agent, waste solid material is taken as the resin concrete mixed by aggregate. The cured product has characteristics of high strength, corrosion resistance, high impermeability and good frost resistance. Among thermosetting plastics, urea-formaldehyde resin is easy to use and has better curing than harmful substances. It is also more widely used because of its good water resistance, corrosion resistance, cheaper price.

Thermoplastic materials refer to those organic materials that can be repeatedly transformed and hardened during heating/cooling, such as asphalt, polyethylene, polyvinyl chloride, polypropylene, paraffin. These materials are hard solids at room temperature, but transfer to plasticity and fluidity at higher temperatures [29].

\subsubsection{Vitrification technology}

Vitrification technology is also called melting and solidification technology, which uses heat energy to melt solid contaminants into glass or glass-ceramic substances at high temperatures. With the dense crystalline structure of the glass body, the solidified body is permanently stabilized. After the contaminants undergo vitrification, 
the organic pollutants will either be destroyed by pyrolysis or converted into gas to escape. The radioactive substances and heavy metals will be firmly bound in the molten glass. The melting and solidification technology is currently a more advanced heavy metal waste slag harmless treatment technology over the world [30].

\subsection{Chemical repair technology}

\subsubsection{Chemical curing technology}

The principle of the chemical solidification technology is to add some solidification agents to the soil to change the form of heavy metals through the reaction between the solidification agent and the soil [31], and to reduce the bioavailability and mobility of the soil, so as to achieve the purpose of reducing the pollution of heavy metals to the soil. The solidifying agent mainly achieves the effect of reducing the pollution of heavy metals on the soil through precipitation, adsorption, coordination, organic complexation and redox with the soil [32].

\subsubsection{Adsorption and coordination}

The principle of clay minerals to treat heavy metal pollution in the soil is to passivate heavy metals through adsorption, coordination and co-precipitation reactions [33] to reduce the bioavailability of heavy metals. Due to the unique spatial structure of zeolite, there are more studies in this area. The passivation effect of zeolite on heavy metals in the soil is related to the type of soil, acidity [34], temperature, time of action, and the type of metal.

\subsubsection{Organic complexation}

Organic matter mainly forms insoluble compounds through organic complexation with the soil to reduce the pollution of heavy metals to the soil. Studies have shown that long-term application of organic fertilizers can increase the number of mineral functional groups in the soil, make more metal ions in the soil complex, reduce the migration of heavy metals in the soil, and thus change the content of heavy metals in the soil [35]. Although this soil remediation method can reduce the bioavailability of metals, the total concentration of metals in the soil has changed. With the occurrence of a series of natural processes such as weathering and decomposition [36], the heavy metals in the soil will be removed again.

\subsubsection{Chemical extraction technology}

The principle of chemical extraction technology is to separate heavy metals from the soil by adding chemical extractants and aqueous solutions, and then remove them. The most commonly used chemical extraction techniques are chelating agent extraction and acid extraction [37]. These substances are relatively inexpensive and less likely to pollute the soil.

The $\mathrm{pH}$ value of the soil should be controlled during the extraction process. If the $\mathrm{pH}$ value of the soil is too high, the heavy metals in the soil cannot exist as ions; however, if the $\mathrm{pH}$ value of the soil is too low, it will damage the physical and chemical properties of soil [38], leading to the loss of nutrients.

The use of chemical technology to treat soil heavy metal pollution has low cost and good effect. However, the research on the mechanism of heavy metal chemical repair technology is not thorough enough to guarantee the stability of the repair effect, and there are still many problems that need to be studied in depth.

\subsection{Bioremediation technology}

Bioremediation is to reduce the content of heavy metals in the soil or reduce the toxicity of heavy metals through the life metabolism activities of plants, animals and microorganisms.[39]

\subsubsection{Phytoremediation technology}

Phytoremediation is an alternative to traditional physical and chemical methods, which use various plants to remove metal (such as $\mathrm{Cd}$ ) contaminated soil on site. The brief principle of phytoremediation is to use special plants in the root system and their corresponding microbial ecosystem to extract, transfer, absorb, transform or stabilize pollutants in the soil, and then reduce the toxicity of metals.

Compared with the technologies including excavation, filling, electric repair, chemical elution, stabilization and curing technology, plant weeding technology usually has economic advantages. However, most of the plants that can be used for restoration are usually small and growing slowly, making it difficult to select and cultivate. In addition, most of the plants that can be used for restoration only have an effective effect on one metal element. Therefore, poor phytoremediation efficiency has resulted in a longer recovery period that usually exceeds 10 years. In addition, phytoremediation techniques can only completely restore the first $50 \mathrm{~cm}$ of slightly polluted topsoil.

The use of phytoremediation of soil is considered to be an effective and low-cost technology to remove $\mathrm{Cd}$ from contaminated soil. However, it is very important to safely and economically dispose of the harvested biomass to avoid secondary environmental pollution. When comparing general disposal methods of contaminated biomass, such as composting, compaction, incineration, ashing, pyrolysis, direct disposal, and liquid extraction, researchers have found that incineration is usually the most recommended choice.

\subsubsection{Microbial remediation technology}

According to the different types of microorganisms, the main effects of microorganisms on heavy metals in soil 
include biosorption and enrichment, redox, precipitation and dissolution.

It is the anionic groups in microorganisms that can adsorb heavy metals in the soil through ion exchange, chelation, complexation, electrostatic adsorption, and covalent adsorption with positively charged heavy metal ions [40].

\subsubsection{Animal repair technology}

Animal repair technology refers to the absorption, transfer or degradation of heavy metals through the food chain of soil animals. There are relatively few studies in this area. Among the more common animal remediation technologies, earthworms are the most studied. The remediation of heavy metal contaminated soil by earthworms has two main aspects: one is the activity of earthworms that can change the structure and permeability of the soil, and promote the transformation of organic matter and microorganisms in the soil; the other is the metabolism of earthworms [41] that can also play an important role to improve soil fertility. And thus, the essence of animal remediation is actually microbial remediation, and it is actually the microorganisms in the soil that can play the role of remediation, but this kind of microorganisms includes the original microorganisms in the soil and the microorganisms in the products of earthworm metabolism.

\subsection{Joint repair}

Due to wide area of metal pollution in the soil and various kinds of pollution elements, it is difficult to complete the repair and remediation purposes by using a single method. Joint repair can make up for the shortcomings of a single method and give full play to the advantages of each technology. Joint repair is combining multiple repair methods to improve the efficiency and rate of removing cadmium, avoiding the limitations of a single repair as well. Commonly used joint repair methods include plant-microbial joint repair, physicalbiological joint repair, chemical-biological joint repair and physical-chemical joint repair.

\subsubsection{Chelating agent-phytoremediation}

Chelating agents can break the combination of heavy metal ions and soil solid phase and resolve metal ions from soil solid phase. They can increase the concentration of heavy metal ions in the soil, improving the efficiency of heavy metal ions removal.

When treating heavy metal pollution, Nitrilotriacetic acid (NTA) can promote the migration of $\mathrm{Zn}, \mathrm{Cu}, \mathrm{Fe}$, $\mathrm{Mn}$, and Cd plasma, especially the effect of treating As,
$\mathrm{Pb}$ and $\mathrm{Cd}$ is more obvious [42]. Ethylene Diamine Tetraacetic Acid (EDTA) can also activate and dissolve metal elements such as $\mathrm{Pb}, \mathrm{Cd}$ and $\mathrm{Zn}$ in the soil, and promote the absorption and accumulation of metals by plants [43]. However, high concentrations of EDTA will inhibit the ability of plants absorbing the heavy metals [44].

When adding different concentrations of acids such as tartaric acid, malic acid, citric acid and oxalic acid, the $\mathrm{Cd}$ content of different organs of the Aronia argentea increased because these low-molecular-weight organic acids can strongly combine with $\mathrm{Cd} 2+$ to form an organic compound, and the organic compound state $\mathrm{Cd}$ is easier to transport and accumulate in plants than ionic $\mathrm{Cd}[45,46]$. The $\mathrm{Cd}$ content in the leaves of Argentea treated with citric acid reaches $143.00 \pm 14.60 \mathrm{mg} / \mathrm{kg}$, 2.74 times that of the control group, and the total absorption amount of citric acid can reach $0.199 \pm 0.006$ $\mathrm{mg} /$ plant which is the highest [46].

\subsubsection{Microbial-phytoremediation}

Microbial-phytoremediation is the process of using plants and their related microorganisms to remove, transfer or stabilize heavy metals, thereby reducing the concentration or toxicity of heavy metals in the soil. Plant growth and its rhizosphere are closely related to endophytic microorganisms. As many microorganisms have evolved the ability to tolerate high $\mathrm{Cd} 2+$ concentrations, they have a strong affinity for $\mathrm{Cd}$ and can even reduce the toxicity of $\mathrm{Cd}$ in the soil along adsorption, precipitation and redox [47].

Arbuscular mycorrhizal fungi (AMF) can not only build the relationship between the soil and plant's roots, but also can affect the plant's absorption of heavy metals [48]. Hu J inoculated two AMF strains Glomus caladium 90036 (Gc) and Glomus mosseae M47v (Gm) on ryegrass (Lolium perenne L.), and found that both Gc and $\mathrm{Gm}$ reduced the soil effective $\mathrm{Cd}$ content by $21 \%$ to $38 \%(\mathrm{P}<0.05)$ [49]. Li $\mathrm{H}$ found that by making rice (Oryza sativa L.) Symbiosis with two kinds of AMF-Rhizophagus intraradices (RI) and Funneliformis mosseae (FM), they found that the symbiosis of AMF and rice can significantly reduce the $\mathrm{Cd}$ concentration in the shoots and roots of plants [50].

There are two kinds of AMF- phytoremediation methods. One is that AMF can promote the plant to absorb $\mathrm{Cd}$ to reduce the concentration, so that the contaminated soil can be cultivated again. The other one is to plant crops with low $\mathrm{Cd}$ absorption on $\mathrm{Cd}$ contaminated soil, and inoculate AMF to enhance the inhibitory effect of crops on $\mathrm{Cd}$ absorption and to reduce the accumulation of $\mathrm{Cd}$ in such crops.

Table 1 The features and application of remediation methods

\begin{tabular}{|c|c|c|c|c|c|}
\hline \multirow{2}{*}{ Type } & \multirow{2}{*}{$\begin{array}{l}\text { Remediation } \\
\text { Methods }\end{array}$} & \multicolumn{2}{|c|}{ Technical features } & \multirow{2}{*}{$\begin{array}{l}\text { Remediation } \\
\text { Time }\end{array}$} & \multirow{2}{*}{$\begin{array}{c}\text { Scope of } \\
\text { Application }\end{array}$} \\
\hline & & Advantages & Disadvantages & & \\
\hline
\end{tabular}




\begin{tabular}{|c|c|c|c|c|c|}
\hline \multirow{7}{*}{ Physical } & Digging and filling & $\begin{array}{l}\text { Low duration heavily } \\
\text { polluted soil; high } \\
\text { efficiency }\end{array}$ & $\begin{array}{l}\text { High cost; destroy soil } \\
\text { structure; soil pollution }\end{array}$ & $\begin{array}{l}\text { Relatively } \\
\text { very short }\end{array}$ & $\begin{array}{l}\text { Large area of } \\
\text { heavily } \\
\text { contaminated } \\
\text { farmland soil }\end{array}$ \\
\hline & $\begin{array}{l}\text { Electro-kinetic } \\
\text { remediation }\end{array}$ & $\begin{array}{l}\text { Low impact on soil; } \\
\text { operate easily; high } \\
\text { efficiency }\end{array}$ & $\begin{array}{l}\text { Change soil properties; } \\
\text { low selectivity to } \\
\text { pollutants; soil } \\
\text { acidification risk; long } \\
\text { duration; high cost }\end{array}$ & $\begin{array}{l}\text { Relatively } \\
\text { very short }\end{array}$ & $\begin{array}{c}\text { Small area of } \\
\text { heavily } \\
\text { contaminated } \\
\text { farmland soil }\end{array}$ \\
\hline & $\begin{array}{l}\text { Frozen soil } \\
\text { technology }\end{array}$ & $\begin{array}{l}\text { Environment friendly; } \\
\text { low duration; quick }\end{array}$ & $\begin{array}{l}\text { Polluted soil can't be } \\
\text { purified; high input cost. }\end{array}$ & $\begin{array}{l}\text { Relatively } \\
\text { very short }\end{array}$ & $\begin{array}{l}\text { Large area of } \\
\text { slightly to } \\
\text { moderately } \\
\text { contaminated } \\
\text { farmland soil }\end{array}$ \\
\hline & Cement curing & $\begin{array}{l}\text { Inhibits penetration of } \\
\text { heavy metals; low cost; } \\
\text { high efficiency }\end{array}$ & $\begin{array}{l}\text { Corrosive effect; poor } \\
\text { acid resistance }\end{array}$ & $\begin{array}{l}\text { Relatively } \\
\text { very short }\end{array}$ & $\begin{array}{l}\text { Large area of } \\
\text { slightly to } \\
\text { moderately } \\
\text { contaminated } \\
\text { farmland soil }\end{array}$ \\
\hline & $\begin{array}{l}\text { Lime/volcanic ash } \\
\text { solidification }\end{array}$ & $\begin{array}{c}\text { good effect to reduce; } \\
\text { better adsorption capacity; } \\
\text { high effectiveness; low } \\
\text { cost }\end{array}$ & $\begin{array}{l}\text { Need to consider the } \\
\text { conditions of different soil } \\
\text { media to determine the } \\
\text { amount of lime used; long } \\
\text { duration }\end{array}$ & $\begin{array}{l}\text { Relatively } \\
\text { short }\end{array}$ & $\begin{array}{l}\text { Large area of } \\
\text { slightly to } \\
\text { moderately } \\
\text { contaminated } \\
\text { farmland soil }\end{array}$ \\
\hline & $\begin{array}{c}\text { Plastic material } \\
\text { containment curing }\end{array}$ & $\begin{array}{l}\text { High strength; high } \\
\text { corrosion resistance; high } \\
\text { impermeability; water } \\
\text { resistance; cheap price }\end{array}$ & Energy costly & $\begin{array}{l}\text { Relatively } \\
\text { short }\end{array}$ & $\begin{array}{l}\text { Large area of } \\
\text { slightly to } \\
\text { moderately } \\
\text { contaminated } \\
\text { farmland soil }\end{array}$ \\
\hline & $\begin{array}{l}\text { Vitrification } \\
\text { technology }\end{array}$ & $\begin{array}{l}\text { Environment friendly; } \\
\text { Rapid heating and energy } \\
\text { saving; high efficiency }\end{array}$ & $\begin{array}{l}\text { High cost; need more } \\
\text { research }\end{array}$ & $\begin{array}{l}\text { Relatively } \\
\text { very short }\end{array}$ & $\begin{array}{l}\text { Large area of } \\
\text { slightly to } \\
\text { moderately } \\
\text { contaminated } \\
\text { farmland soil }\end{array}$ \\
\hline \multirow{3}{*}{ Chemical } & $\begin{array}{l}\text { Adsorption and } \\
\text { coordination }\end{array}$ & $\begin{array}{l}\text { Convenient, fast, } \\
\text { effective, economical and } \\
\text { practical; not change the } \\
\text { total content of heavy } \\
\text { metals; reduce the } \\
\text { migration and toxicity of } \\
\text { heavy metals }\end{array}$ & $\begin{array}{c}\text { Complex influencing } \\
\text { factors: the type of soil, } \\
\text { acidity, temperature, time } \\
\text { of action, and the type of } \\
\text { metal }\end{array}$ & $\begin{array}{l}\text { Short to } \\
\text { medium term }\end{array}$ & $\begin{array}{c}\text { Small area of } \\
\text { heavily } \\
\text { contaminated } \\
\text { farmland soil }\end{array}$ \\
\hline & $\begin{array}{c}\text { Organic } \\
\text { complexation }\end{array}$ & $\begin{array}{l}\text { Increase the number of } \\
\text { mineral functional groups }\end{array}$ & $\begin{array}{c}\text { Change the total } \\
\text { concentration of metals in } \\
\text { the soil; may be affected } \\
\text { by weathering and } \\
\text { decomposition }\end{array}$ & $\begin{array}{c}\text { Short to } \\
\text { medium term }\end{array}$ & $\begin{array}{l}\text { Small area of } \\
\text { heavily } \\
\text { contaminated } \\
\text { farmland soil }\end{array}$ \\
\hline & $\begin{array}{l}\text { Chemical } \\
\text { extraction } \\
\text { technology }\end{array}$ & $\begin{array}{l}\text { Inexpensive; not easy to } \\
\text { pollute the soil; various } \\
\text { selection of extraction } \\
\text { agents; high removal rates }\end{array}$ & $\begin{array}{l}\text { Complex influencing } \\
\text { factor: } \mathrm{pH} \text {; not thorough } \\
\text { enough to guarantee the } \\
\text { stability of the repair } \\
\text { effect }\end{array}$ & $\begin{array}{l}\text { Short to } \\
\text { medium term }\end{array}$ & $\begin{array}{c}\text { Small area of } \\
\text { heavily } \\
\text { contaminated } \\
\text { farmland soil }\end{array}$ \\
\hline Bioremediation & $\begin{array}{l}\text { Phytoremediation } \\
\text { technology }\end{array}$ & $\begin{array}{c}\text { Economic advantages; } \\
\text { effective and low-cost } \\
\text { technology; avoid } \\
\text { secondary environmental } \\
\text { pollution }\end{array}$ & $\begin{array}{l}\text { Small and slow growing; } \\
\text { difficult to select and } \\
\text { cultivate; only have an } \\
\text { effective effect on one } \\
\text { metal element; longer } \\
\text { recovery period }\end{array}$ & Long & $\begin{array}{l}\text { Large area of } \\
\text { slightly to } \\
\text { moderately } \\
\text { contaminated } \\
\text { farmland soil }\end{array}$ \\
\hline
\end{tabular}




\begin{tabular}{|c|c|c|c|c|c|}
\hline & $\begin{array}{l}\text { Microbial } \\
\text { remediation } \\
\text { technology }\end{array}$ & $\begin{array}{l}\text { Adsorb heavy metals in } \\
\text { the soil through ion } \\
\text { exchange, chelation, } \\
\text { complexation, } \\
\text { electrostatic adsorption, } \\
\text { and covalent adsorption } \\
\text { with positively charged } \\
\text { heavy metal ions }\end{array}$ & $\begin{array}{l}\text { Complex influencing } \\
\text { factors: temperature, } \mathrm{pH} \text {, } \\
\text { inorganic salt } \\
\text { concentration; Most } \\
\text { pollutants are non-water } \\
\text { soluble, not easy to mix } \\
\text { and contact with } \\
\text { microorganisms }\end{array}$ & Long & $\begin{array}{l}\text { Large area of } \\
\text { slightly to } \\
\text { moderately } \\
\text { contaminated } \\
\text { farmland soil }\end{array}$ \\
\hline & $\begin{array}{l}\text { Animal repair } \\
\text { technology }\end{array}$ & $\begin{array}{l}\text { Change the structure and } \\
\text { permeability of the soil; } \\
\text { promote the } \\
\text { transformation of organic } \\
\text { matter and } \\
\text { microorganisms }\end{array}$ & $\begin{array}{l}\text { Few studies; mostly like } \\
\text { microbial remediation } \\
\text { technology; high cost }\end{array}$ & Long & $\begin{array}{l}\text { Large area of } \\
\text { slightly to } \\
\text { moderately } \\
\text { contaminated } \\
\text { farmland soil }\end{array}$ \\
\hline \multirow[b]{2}{*}{ Joint repair } & $\begin{array}{l}\text { Chelating agent- } \\
\text { phytoremediation }\end{array}$ & $\begin{array}{l}\text { Break the combination of } \\
\text { heavy metal ions and soil } \\
\text { solid phase; resolve metal } \\
\text { ions; increase the } \\
\text { concentration of heavy } \\
\text { metal ions in the soil }\end{array}$ & $\begin{array}{l}\text { High concentrations will } \\
\text { inhibit the ability of plants } \\
\text { absorbing the heavy } \\
\text { metals; long duration; } \\
\text { various effect factors for } \\
\text { different kinds of plants }\end{array}$ & Long & $\begin{array}{l}\text { Large area of } \\
\text { slightly to } \\
\text { moderately } \\
\text { contaminated } \\
\text { farmland soil }\end{array}$ \\
\hline & $\begin{array}{c}\text { Microbial- } \\
\text { phytoremediation }\end{array}$ & $\begin{array}{l}\text { Microorganisms have the } \\
\text { ability to tolerate high } \\
\mathrm{Cd} 2+\text { concentrations; } \\
\text { reduce the toxicity of } \mathrm{Cd} \\
\text { in the soil; build the } \\
\text { relationship between the } \\
\text { soil and plant's roots }\end{array}$ & $\begin{array}{l}\text { Microoganism may cause } \\
\text { extra pollution to soil; } \\
\text { long duration; disturbance } \\
\text { of the normal crop } \\
\text { cultivation }\end{array}$ & Long & $\begin{array}{l}\text { Large area of } \\
\text { slightly to } \\
\text { moderately } \\
\text { contaminated } \\
\text { farmland soil }\end{array}$ \\
\hline
\end{tabular}

\section{Discussion}

\subsection{Controlling factors}

For the remediation of Cd-rich soil, the choice of technology is particularly important. Table 1 compares the choice and applicability of the remediation technology. It can be seen that the application and selection of different treatment technologies depend on various factors such as the area of Cd-rich soil, the content of $\mathrm{Cd}$ pollutants, and the treatment time.

\subsection{Advantages and disadvantages}

Physical remediation methods are generally suitable for small-scale contaminated sites, but they are generally not suitable for agricultural areas due to their destructiveness and loss of soil fertility. The chemical remediation method can be applied to large-contaminated areas but it also has serious drawbacks. This is because numerous chemical reagents are used in the remediation process and such big amount will cause so many chemical to flow into the soil that improper control will cause secondary pollution and lead to heavy metals in the soil increase the scale of pollution. The bioremediation method requires less cost in the treatment of soil heavy metal pollution, and it is easy to obtain good treatment effects. In addition, the operation in the treatment process is simple, so it is widely used. One of its shortcomings is that it needs a long period of governance, and thus it takes a long time to be effective.

\subsection{Future orientation}

It is necessary to make scientific selections based on local actual conditions and to focus on the joint application of multiple methods in order to achieve the best treatment effects of heavy metals and promote soil recovery. According to different kinds of remediation methods, we can find more efficient ways to solve this problem.

\section{Conclusion}

Heavy metal pollution of farmland soil is becoming an increasingly severe issue, not just in China but all around the world. Pollution has led to the decline of agricultural economy and the instability of social economy. In particular, the Chinese government has made tremendous efforts in the remediation of Contaminated Farmland Soil and provided special funds for research and development of farmland remediation and related remediation technologies.

In this paper, recent progress in the field of electrokinetic remediation, chemical elution, solidification and stabilization, and phytoremediation processes is reviewed. Most repair studies are based on laboratory and pilot tests, especially electric repair and chemical elution. For the polluted farmland soil, there is no advanced commercial remediation technology in China. Bioremediation technology and Joint repair technology are the new ways to restore cadmium enriched farmland. However, it would take so many painstaking researches to achieve transfer of learning, that is, to apply theories and concepts of technologies from concept to practice in 
real life. Therefore, further research and development are still in demand.

\section{References}

1. Zhang Xin, Fan Zhongxue, Guo Dufa, et al. Effects of three microbial agents on the growth of spinach in mildly cadmium-contaminated soil[J]. Tianjin Agricultural Sciences, 2011, 17(1): 81-83, 87.

2. Zeng Xiangfeng, Wang Zuwei. Experimental study on the removal of cadmium in urban sludge[J]. Tianjin Agricultural Sciences, 2011, 17(1): 117-119.

3. Ministry of Environmental Protection, Ministry of Land and Resources. National Soil Pollution Survey Bulletin[R]. China: Ministry of Environmental Protection, Ministry of Land and Resources, 2014.

4. Song Chunran, He Jinlin, Tan Hong, et al. Preliminary evaluation of heavy metal pollution in agricultural soils in Guizhou Province[J]. Guizhou Agricultural Sciences, 2005, 33(2): 13-16.

5. Yong, Zhong Gemei, Huang Jiangping, et al. Survey of cadmium content in farmland soils in Guangxi from 2001 to $2013[\mathrm{~J}]$. Journal of Environmental Hygiene, 2014, 4(6): 544-547.

6. Tian Xiuhong. Research progress of heavy metal pollution in vegetables in the suburbs of my country[J]. Food Science, 2009, 30(21):449-453.

7. Peng Shaobang, Cai Le, Li Siqing. Research progress in soil cadmium pollution remediation methods and bioremediation[J]. Environment and Development, 2014, 26(3): 86-90.

8. Xu Jialin, Yang Jurong. Heavy metals in terrestrial ecosystem[M]. Beijing: China Environmental Science Press, 1995.

9. Li Jing, Zhou Yanwen, Chen Sen, Gao Xiaojie. Summary of the status, harm and control methods of soil cadmium pollution in my country[J].Anhui Agricultural Science Bulletin,2015,21(24):104-107.

10. Zeng Yongmei, Mao Kunming, Li Yongmei. The Harm of Cadmium Pollution in Soil and Its Countermeasures[J]. Journal of Yunnan Agricultural University, 2005, 20(3): 360-365.

11. Peng Xinghui, Xie Xiaoyang. Research progress on soil remediation technology of cadmium (Cd) contaminated paddy field[J].Hunan Agricultural Sciences, 2007 (2): 67-69.

12. Gao Zhiling, Liu Jianling, Liao Wenhua. Research status and prevention of phosphate fertilizer use and cadmium pollution Countermeasures $[\mathrm{J}]$. Journal of Hebei Agricultural University, 2001, 24(3): 90-99.

13. Tang X, Li Q, Wu M, et al. Review of remediation practices regarding cadmium-enriched farmland soil with particular reference to China [J]. J Environ Manag, 2016, 181: 646662.

14. Li JR, Xu YM. Immobilization remediation of Cdpolluted soil with different water condition $[\mathrm{J}]$. J Environ Manag, 2017, 193: 607612.
15. Gorospe J. Growing greens and soiled soil: Trends in heavy metal contamination in vegetable gardens of san Francisco [D]. America: San José State University, 2012.

16. Chen, Y.J., Fang, L.N., Yang, J.Y., 2014. The cropland pollution in China: status and countermeasures. Chin. J. Agric. Res. Reg. Plan. 35, $1 \mathrm{e} 5$.

17. Suer, Y.B., Gitye, K., Allard, B., 2003. Speciation and transport of heavy metals and macroelements during electroremediation. Environ. Sci. Technol. 37, $177 \mathrm{e} 181$.

18. Probstein, R.F., Hicks, R.E., 1993. Removal of contaminants from soils by electric fields. Science 260, $498 \mathrm{e} 503$.

19. Gomes, H.I., Dias-Ferrira, C., Ribero, A.B., 2012. Electrokinetic remediation of or- ganochlorines in soil: enhancement techniques and integration with other remediation technologies. Chemosphere 87, $1077 \mathrm{e} 1090$.

20. Zhao Jinglian. Principles and Technology of Environmental Remediation[M]. Beijing: Chemical Industry Press, 2006.

21. Du Yanjun, Jin Fei, Liu Songyu, et al. Research progress on solidification/stabilization of contaminated sites in heavy metal industry[J]. Rock and Soil Mechanics, 2011, 32(1): 116-124.

22. Hao Hanzhou, Chen Tongbin, Jin Menggui, et al. Research progress of heavy metal contaminated soil stabilization/solidification technology[J]. Chinese Journal of Applied Ecology, 2011, 22(3):816-824.

23. EPA. Technology Performance Review: Selecting and Using Solidification/Stabilization Treatment for Site Re- mediation (EPA EPA/600/R-09/148). Washington: EPA, 2009.

24. Malviya R, Chaudhary R. Leaching behavior and immo- bilization of heavy metals in solidified / stabilized prod- ucts. Journal of Hazardous Materials, 2006, 137: 207-217.

25. Bishop P, Gress D, Olafsson J. Cement stabilization of heavy metals: Leaching rate assessment. Industrial Wastes-Proceedings of the 14th MidAtlantic Industrial Waste Conference, Lancaster, PA, 1982: 80 - 98 .

26. Shively W, Bishop P, Gress D, et al. Leaching tests of heavy metals stabilized with portland cement. Journal of Water Pollution Control Federation, 1986, 38: 234-241.

27. Chen QY, Tyrer M, Hills CD, et al. Immobilisation of heavy metal in cement-based solidification/stabilisation: A review. Waste Management, 2009, 29: 390 - 403.

28. Naidu R, Kookana RS, Sumner ME. Cadmium sorption and transport in variable charge soils. Journal of Environmental Quality, 1997, 26: 602 617.

29. Simeonova A, Petkov A, Balgaranova J. Stabilization of sludge from electroplating of plastic 
materials for safe disposal and utilization. Journal of the University of Chemical Technology and Metallurgy, 2006, 41: 107 - 110.

30. Smith LA, Means JL, Chen A, et al. Remedial Options for Metals-Contaminated Sites. FL: Boca Raton, 1995.

31. Li Ning, Ren Bozhi, Zhou Yingying, et al. Research on soil heavy metal pollution hazards and remediation methods[J]. Guangzhou Chemical Industry, 2017, 45(9): 30-32.

32. Sun Pengcheng, Huang Zhanbin, Tang Ke, et al. Research progress in chemical solidification of soil heavy metal pollution control[J]. Environmental Engineering, 2014, 32(1):158-161.

33. Li Jianrui, $\mathrm{Xu}$ Yingming, Lin Dasong, et al. Research progress in in-situ passivation remediation of heavy metal pollution in farmland[J]. Journal of Ecological Environment, 2014, 23(4):721-728.

34. Yang Xiuli, Wang Xuejie. Chemical treatment and restoration of soil contaminated by heavy metals[J]. Journal of Zhejiang Education Institute, 2002(2):5561.

35. Sun Fusheng. Study on the content of heavy metals and their complexing mechanism in soil with longterm located fertilization[D]. Nanjing: Nanjing Agricultural University, 2015.

36. Wu Xue, Zhao Li, Ding Lin. The application of organic amendments in the remediation of heavy metal contaminated soil[J]. Southern Agriculture, 2017, 11(12):119-122.

37. Qi Miao. Chemical extraction technology in the remediation of heavy metal contaminated soil[J]. Regional Management, 2019(4):67-68.

38. Peng Da. Chemical extraction technology in the remediation of heavy metal contaminated soil[J]. Environmental Governance and Development, 2018(25):53-54.

39. Wen Zhiliang, Mao Youfa, Chen Guizhu. Research on biological restoration technology of heavy metal pollution[J]. Environment and Sustainable Development, 1999(3):15-17.

40. Zhang Caili. Research progress on microbial remediation of heavy metal contaminated soil[J]. Journal of Anhui Agricultural Sciences, 2015, 43(16): 225-229.

41. Wang Na. Research progress in the application of earthworms and their metabolites in the remediation of heavy metal contaminated soils[J]. Modern Agricultural Science and Technology, 2018, 732(22): 194-195.

42. Wei Sixiang. Research progress on the application of chelating agents and combined substances in phytoremediation of heavy metal contaminated soil[J].Guangdong Chemical Industry, 2013, 40(19): 84-85+90.

43. Ebbs S D, Kochian L V. 1998. Phytoextraction of zinc by oat (Avena sativa), barley (Hordeum vulgare), and Indian mustard (Brassica juncea) $[\mathrm{J}]$.
Environmental Science \& Technology, 32 (6): 802806.

44. Chen H, Cutright T. 2001. EDTA and HEDTA effects on $\mathrm{Cd}, \mathrm{Cr}$, and $\mathrm{Ni}$ uptake by Helianthus annuus[J]. Chemosphere, $45: 21-28$.

45. Ehsan S, Ali S, Noureen S,M ahmood K, Farid M, Ishaque W, Shakoor M B, Rizwan M. 2014. Citric acid assisted phytoremediation of cadmium by Brassica napus L[J]. Ecotoxicology and Environmental Safety, 106 : 164-172.

46. Jiang Pingping, Yu Guo, et al. Effects of Different Chelating Agents on the Remediation of Soil Cadmium Pollution by Celosia argentea[J].Journal of Southern Agricultural Sciences, 2019, 50(11): 2443- 2449.

47. Yi Zefu, Yu Xing, Wu Jing. Research progress of cadmium contaminated soil remediation technology $[\mathrm{J}]$. modern agriculture Science and Technology, 2014 (9): 251-253

48. Shi Hao, Peng An'an, Yu Chunmu. Research progress of microbe-phytoremediation of cadmium contaminated soil[J].Guangzhou Chemical Industry, 2020, 48(06): 36-39.

49. $\mathrm{Hu} \mathrm{J}, \mathrm{Wu} \mathrm{S}, \mathrm{Wu} \mathrm{F}$, et al. Arbuscular mycorrhizal fungi enhance both absorption and stabilization of Cd by Alfred stonecrop ( Sedum alfredii Hance) and perennial ryegrass ( Lolium perenne L.) in a Cdcontaminated acidic soil[J]. Chemosphere, 2013, 93( 7) : 1359-1365

50. Li H, Luo N, Zhang L J, et al. Do arbuscular mycorrhizal fungi affect cadmium uptake kinetics, subcellular distribution and chemical forms in rice? [J]. Science of the Total Environment, 2016, 571: 1183-1190. 